\title{
A review of 11 years of Stenotrophomonas maltophilia blood isolates at a tertiary care institute in Canada
}

\author{
Prenilla Naidu MBChB ${ }^{1}$, Stephanie Smith MSc MD FRCPC ${ }^{2}$
}

\begin{abstract}
P Naidu, S Smith. A review of 11 years of Stenotrophomonas maltophilia blood isolates at a tertiary care institute in Canada. Can J Infect Dis Med Microbiol 2012;23(4):165-169.
\end{abstract}

BACKGROUND: Stenotrophomonas maltophilia has emerged as a significant nosocomial pathogen with increasing resistance to trimethoprim/sulphamethoxazole (TMP/SMX), the current drug of choice for treatment.

OBJECTIVES: To describe the microbiological and clinical characteristics of S maltophilia bloodstream infections (BSIs) over an 11-year period at a tertiary care centre in Canada.

METHODS: All adult S maltophilia BSIs from 1999 to 2009 in a 750-bed tertiary care teaching hospital (University of Alberta Hospital, Edmonton, Alberta) were identified through the infection control nosocomial infection surveillance program. Demographic and clinical data were extracted from the infection control database and from patient charts. Microbiological data were confirmed through the laboratory information system.

RESULTS: Twenty-five episodes of S maltophilia BSI (0.9\% of all BSIs) involving 24 patients were identified between 1999 and 2009. The patient age range was 18 to 83 years (average 45.7 years). The majority were men (14 of 24 [58.3\%]). The mean length of hospital stay was 83.3 days (range eight to 310 days). The rate of S maltophilia BSIs per 1000 admissions ranged from 0.04 to 0.22 (average 0.09 ). Greater than one-half of the episodes (13 of 25 [52\%]) were admitted to the intensive care unit before BSI onset. Laboratory data were available for 24 of the 25 isolates. Polymicrobial infections were present in 11 of $24(45.8 \%)$ patients. Resistance to TMP/SMX occurred in $8.3 \%$ of all infections. Fifteen per cent of isolates were resistant to ticarcillin/ clavulanate. Mortality attributed to bacteremia was $16.7 \%$.

CONCLUSIONS: In the University of Alberta Hospital, the rate of $S$ maltophilia BSI remains low and constant, and TMP/SMX remains the drug of choice for treatment.

Key Words: Bloodstream infections; Catheter-related infections; Stenotrophomonas

Ctenotrophomonas maltophilia has emerged as a significant opportunistic $S_{\text {pathogen in hospital settings. Although it is not considered part of the }}$ normal microbial flora of humans, it can form part of the transitory colonizers of hospitalized patients, which commonly colonize the respiratory and gastrointestinal tracts (1). The intrinsic resistance of S maltophilia to many antimicrobials and commonly used disinfectants makes its eradication from aquatic and humid hospital environments challenging. Current literature suggests an increasing rate of S maltophilia nosocomial infections (2), as well as increasing resistance to trimethoprim/sulphamethoxazole (TMP/SMX) $(1,3)$, the current drug of choice for treatment. There are few data in the literature describing the Canadian experience with this pathogen and few studies investigating the hospital-wide incidence of S maltophilia bloodstream infections (BSIs).

\author{
Une analyse des isolats de Stenotrophomonas \\ maltophilia dans le sang, prélevés sur une période \\ de onze ans dans un établissement de soins \\ tertiaires du Canada
}

HISTORIQUE : Le Stenotrophomonas maltophilia a émergé comme un pathogène nosocomial important de plus en plus résistant au triméthoprimsulphaméthoxazole (TMP-SMX), le traitement de choix actuel.

OBJECTIFS : Décrire les caractéristiques microbiologiques et cliniques des infections du sang (IS) à $S$ maltophilia sur une période de onze ans dans un centre de soins tertiaires du Canada.

MÉTHODOLOGIE : Les chercheurs ont retenu tous les adultes ayant contracté une IS à S maltophilia entre 1999 et 2009 dans un hôpital d'enseignement de soins tertiaires de 750 lits (University of Alberta Hospital, Edmonton, Alberta) par le programme de surveillance des infections nosocomiales du Contrôle des infections. Ils ont tiré les données démographiques et cliniques des bases de données du Contrôle des infections et des dossiers des patients. Ils ont confirmé les données microbiologiques par le système d'information en laboratoire.

RÉSULTATS : Les chercheurs ont constaté 25 épisodes d'IS à $S$ maltophilia (0,9\% de toutes les IS), touchant 24 patients entre 1999 et 2009. Les patients avaient de 18 à 83 ans (moyenne de 45,7 ans), étaient majoritairement de sexe masculin (14 sur 24 [58,3\%]) et ils avaient été hospitalisés pendant une durée moyenne de 83,3 jours (plage de huit à 310 jours). Le taux d'IS à $S$ maltophilia sur 1000 hospitalisations oscillait entre 0,04 et 0,22 (moyenne 0,09 ). Plus de la moitié des épisodes (13 sur 25 [52\%]) s'étaient produits chez des patients hospitalisés à l'unité de soins intensifs avant l'apparition de l'IS. Les chercheurs possédaient les données de laboratoire de 24 des 25 isolats et ont relevé des infections polymicrobiennes chez 11 des 24 patients (45,8\%). Ils ont observé une résistance au TMP-SMX dans 8,3 \% de toutes les infections. Quinze pour cent des isolats étaient résistants à la ticarcilline-clavulanate. La mortalité attribuée à la bactériémie s'élevait à 16,7 \%.

CONCLUSIONS : À l'University of Alberta Hospital, le taux d'IS à $S$ maltophilia demeure faible et constant, et le TMP-SMX demeure le médicament de choix pour traiter cette infection.

The aim of the present study was to describe the microbiological and clinical characteristics of S maltophilia BSIs over an 11-year period at the University of Alberta Hospital (UAH) in Edmonton, Alberta.

\section{METHODS}

All adults ( $\geq 17$ years of age) with S maltophilia BSIs from January 1999 to December 2009 were identified through the UAH infection control nosocomial infection surveillance program. The UAH is a 750-bed tertiary care teaching hospital serving the population of western and northern Canada and treating more than 700,000 patients annually. Demographic (age, sex, dates of admission and discharge, duration of admission) and clinical (dates of positives blood cultures, duration of $S$ maltophilia bacteremia, comorbidities, admission to the intensive

${ }^{1}$ Department of Medical Microbiology and Immunology; ${ }^{2}$ Division of Infectious Diseases, University of Alberta, Edmonton, Alberta

Correspondence: Dr Stephanie Smith, 2E4.16, WMC, University of Alberta, 8440-112 Street, Edmonton, Alberta T6G $2 B 7$.

Telephone 780-407-2826, fax 780-407-7137, e-mail ss@ualberta.ca 


\section{TABLE 1}

Patient demographics $(n=24)$

\begin{tabular}{lc}
\hline Characteristic & \\
\hline Age, years, mean (range) & $45.7(18-83)$ \\
Sex & $14(58.3)$ \\
Male & $10(41.7)$ \\
Female & \\
Nomorbidities & $3(12.5)$ \\
Hematological malignancies & $2(8.3)$ \\
Burns & $4(16.7)$ \\
Post-transplant & $4(16.7)$ \\
Chronic renal faliure & $2(8.3)$ \\
Diabetes & $2(8.3)$ \\
Other & $7(29.2)$ \\
Intensive care unit & \\
Admission & $13(54.2)$ \\
Intubation & $13(54.2)$ \\
Duration of hospitalization before bacteremia, \\
days, mean (range) \\
Length of hospital stay, days, mean (range) \\
\hline Data presented
\end{tabular}

Data presented as $n$ (\%) unless otherwise indicated. *Diamond-Blackfan syndrome $(n=1)$, heart disease $(n=3)$, Hemophilia $A(n=1)$, syncope with a pacemaker $(n=1)$, pre-bone marrow transplant for myelodysplasia $(n=1)$

care units [ICUs]) were extracted from the infection control database and from individual patient charts.

Microbiological data (isolates from other sites, susceptibility results, coisolated organisms) were confirmed through the laboratory information system. The identification of these isolates was performed by the hospital laboratory using various automated systems during the 11-year period including Vitek 1 (bioMérieux Inc, USA), the BD Phoenix (BD Diagnostics, USA) and Vitek 2 (bioMérieux Inc, USA) systems; the specific years over which these systems were used were not available. Susceptibility testing was initially performed using the Etest (bioMérieux SA, France). Only isolates from 2005 to 2009 were available for repeat susceptibility testing by Etest. The Clinical Laboratory Standards Institute (CLSI, M100-S20, Table 2B-4) breakpoints were used for susceptibility testing interpretation. These isolates were retested against TMP/SMX, ticarcillin/clavulanate and doxycycline.

\section{RESULTS}

Twenty-five episodes of S maltophilia BSI involving 24 patients were identified between January 1, 1999, and December 31, 2009. The age of the patients ranged from 18 to 83 years, with an average of 45.7 years. The majority were men (14 of 24 [58.3\%]). The average length of hospital stay was 83.3 days (range eight to 310 days) (Table 1). The rate of S maltophilia BSIs per 1000 admissions ranged from 0.04 to 0.22 , with an average rate of 0.09 (Figure 1). S maltophilia BSIs represented $0.05 \%$ of all nosocomial BSIs in 2006 and $0.1 \%$ from 2007 to 2009. Fifty-six per cent ( 14 of 25 ) of the episodes were considered to be primary BSIs; $86 \%$ (12 of 14) of these were central line associated (as defined by the National Hospital Surveillance Network [4]). The remaining $44 \%$ ( 11 of 25 ) of episodes were secondary BSIs, the majority of which were secondary to lung infections (six of 11 [55\%]); 36\% were secondary to burns and gastrointestinal sources (18\% for each), and $9 \%$ were secondary to urinary tract infections.

Fewer than than one-half of the episodes (12 of 25 [48\%]) had an associated febrile response, with temperatures $>38^{\circ} \mathrm{C}$, to the bacteremic episodes.

The mean duration of hospitalization before development of an $S$ maltophilia BSI was 40.5 days (range two to 211 days). One patient with two S maltophilia BSIs developed them on day 17 and day 211 . The duration of bacteremia ranged from one to seven days with an average of 3.5 days (calculated from the date of the first positive blood

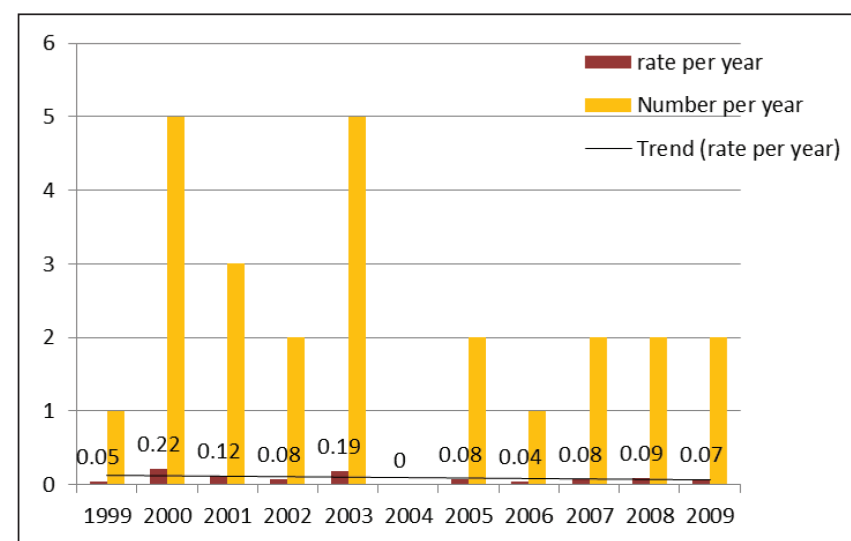

Figure 1) Number and rate of Stenotrophomonas maltophilia bloodstream infections (per 1000 admissions)

culture to the date of the first negative blood culture). In greater than one-half of the episodes, patients were admitted to the ICU (13 of 25 [52\%]) before BSI onset and all patients admitted to the ICU required mechanical ventilation. All of the patients were on antibiotics before developing an S maltophilia BSI, either for a previous infection or as empirical treatment for sepsis.

The comorbidities identified were: burns (four of 24 patients $[16.7 \%]$ ), hematological malignancies (five cases, two of whom had received chemotherapy before developing the S maltophilia $\mathrm{BSI}$ ), transplants (five of 24 [20.8\%]), neutropenia (six of 24 [25\%]), chronic renal failure (three of 24 [12.5\%]; two of whom were on hemodialysis) and diabetes (two of 24 [8.3\%]). The three patients with no comorbidities were hospitalized due to severe trauma (Table 1).

The majority of $S$ maltophilia BSIs were treated with TMP/SMX (20 of 25 [80\%]). One episode was treated with gentamicin and four episodes were not treated (Table 2). Of the patients who were not treated, one was transferred to a subacute care facility before the blood culture became positive and, thus, may have been treated in the community; one was placed on compassionate care shortly after the blood cultures were drawn; one died before the blood cultures became positive; and one was deemed by the admitting service to be a contaminant. This patient cleared their bacteremia without antimicrobial treatment and experienced the second S maltophilia bacteremia six months later.

Laboratory data were available for 24 of the 25 isolates. The average number of positive blood cultures per episode was five (range one to eight). Polymicrobial infections were present in 11 of 24 (45.8\%) episodes, with Enterococcus species and coagulase-negative staphylococci (four of 11 [36\% each]) being the most frequently coisolated organisms. Klebsiella pneumoniae, Staphylococcus aureus, Pseudomonas aeruginosa, Bacteroides fragilis and Ochrobactrum anthropi were the other species isolated.

Susceptibility testing was performed for only two antimicrobials during this 11-year period, TMP/SMX and ticarcillin/clavulanate. Only two of $24(8.33 \%$ ) isolates (one in each of 2005 and 2006) were resistant to TMP/SMX. A total of six isolates were resistant to ticarcillin/ clavulanate; eight were intermediate and nine were susceptible. All isolates tested against minocycline (13 of 13) and tetracycline (six of six) were resistant to these drugs. Susceptibility testing of $S$ maltophilia against doxycycline started in 2005 and five of the eight isolates were susceptible, one was intermediate and two were resistant. There were numerous different laboratory methodologies used for minimum inhibitory concentration (MIC) calculations and reporting during this 11-year period, thus, interpretation and assessment of MIC creep for TMP/SMX was not possible on retrospective review. On all repeat susceptibility testing of the nine isolates from 2005 to 2009, the MICs for the susceptible TMP/SMX isolates were $2.52 \mathrm{mg} / \mathrm{L}$ (Table 3).

A review of the data revealed that $75 \%$ of the episodes resolved with the patients eventually being discharged. Mortality attributable to BSIs was $16.7 \%$ (four of 24 ), with a crude mortality of $25 \%$ (six of 24 ). All 
TABLE 2

Summary of patient data

\begin{tabular}{|c|c|c|c|c|c|c|c|}
\hline Year & Sex & $\begin{array}{c}\text { Age, } \\
\text { years }\end{array}$ & $\begin{array}{l}\text { Admission } \\
\text { diagnosis }\end{array}$ & ICU & $\begin{array}{l}\text { TMPI } \\
\text { SMX }\end{array}$ & Treatment & Outcome \\
\hline 1999 & $M$ & 24 & Burns & Yes & $S$ & TMP/SMX & Resolved \\
\hline 2000 & M & 29 & Trauma & Yes & S & TMP/SMX & Resolved \\
\hline 2000 & F & 58 & ARDS & Yes & S & TMP/SMX & Resolved \\
\hline 2000 & $F^{*}$ & 60 & $\begin{array}{l}\text { Febrile } \\
\text { neutropenia }\end{array}$ & No & $S$ & NT & Resolved \\
\hline 2000 & $\mathrm{~F}^{\dagger}$ & 24 & Burns & Yes & S & NT & Resolved \\
\hline 2001 & $\mathrm{~F}^{\dagger}$ & 25 & Burns & Yes & $\mathrm{s}$ & TMP/SMX & Resolved \\
\hline 2001 & $\mathrm{~F}$ & 62 & $\begin{array}{l}\text { Multiorgan } \\
\text { failure }\end{array}$ & Yes & $\mathrm{s}$ & TMP/SMX & Deceased \\
\hline 2001 & $M$ & 32 & Burns & Yes & S & TMP/SMX & Deceased \\
\hline 2002 & M & 59 & Stroke & No & S & TMP/SMX & Discharged \\
\hline 2002 & $\mathrm{M}$ & 33 & Trauma & Yes & S & TMP/SMX & Resolved \\
\hline 2003 & M & 83 & Sepsis & No & $\mathrm{S}$ & TMP/SMX & Discharged \\
\hline 2003 & M & 51 & $\begin{array}{l}\text { Febrile } \\
\text { neutropenia }\end{array}$ & No & $\mathrm{S}$ & TMP/SMX & Resolved \\
\hline 2003 & M & 28 & Sepsis & Yes & S & Gentamicin & n Deceased \\
\hline 2003 & M & 73 & $\begin{array}{l}\text { Surgical } \\
\text { infection }\end{array}$ & Yes & S & TMP/SMX & Deceased \\
\hline 2003 & $F$ & 37 & $\begin{array}{c}\text { Small bowel } \\
\text { obstruction }\end{array}$ & No & S & TMP/SMX & Resolved \\
\hline 2005 & $M$ & 18 & $\begin{array}{l}\text { Acute } \\
\text { abdomen }\end{array}$ & Yes & $\mathrm{R}$ & TMP/SMX & Resolved \\
\hline 2005 & M & 26 & Burns & Yes & $\mathrm{s}$ & TMP/SMX & Resolved \\
\hline 2006 & $\mathrm{M}^{\ddagger}$ & 39 & $\begin{array}{l}\text { Pulmonary } \\
\text { hemorrhage }\end{array}$ & Yes & $\mathrm{R}$ & NT & Deceased \\
\hline 2007 & $\mathrm{~F}$ & 83 & $\mathrm{CHF}$ & No & S & TMP/SMX & Discharged \\
\hline 2007 & $\mathrm{~F}$ & 48 & MVR & No & S & TMP/SMX & Resolved \\
\hline 2008 & M & 22 & Hemarthrosis & sNo & S & TMP/SMX & Discharged \\
\hline 2008 & $F^{\S}$ & 68 & $\begin{array}{l}\text { Febrile } \\
\text { neutropenia }\end{array}$ & No & S & NT & Deceased \\
\hline 2009 & $M$ & 44 & AML & No & S & TMP/SMX & Resolved \\
\hline 2009 & $\mathrm{~F}$ & 37 & $\begin{array}{l}\text { Pacemaker } \\
\text { infection }\end{array}$ & No & S & TMP/SMX & Resolved \\
\hline
\end{tabular}

${ }^{*}$ Patient was transferred to another facility before blood culture became positive; ${ }^{\dagger}$ Patient with two episodes of Stenotrophomonas maltophilia bloodstream infections, with the first one left untreated because it was deemed a contaminant; ${ }^{\ddagger}$ Patient died before blood culture became positive; ${ }^{S}$ Patient was on compassionate care and the bacteremia was not treated (NT). AML Acute myeloid leukemia; ARDS Acute respiratory distress syndrome; CHF Congestive heart failure; ICU Intensive care unit; MVR Mitral valve replacement; $R$ Resistant to trimethoprim/sulphamethoxazole (TMP/SMX); S Susceptible to $T M P / S M X$

four patients who died due to sepsis had polymicrobial bacteremias. Polymicrobial infections had a mortality rate of $45.5 \%$ (five of 11 ) as opposed to monomicrobial infections (7.7\% [one of 13]).

\section{DISCUSSION}

An increase in incidence of severe infections with $S$ maltophilia has been reported in the literature $(5,6)$. This is believed to be due to the increasing pool of susceptible patients being treated more aggressively for malignancies and connective tissue diseases, resulting in prolonged and profound immunosuppression, the increasing use of broad-spectrum $\beta$-lactam antibiotics and assisted ventilation. $S$ maltophilia was the third most frequently reported glucose nonfermenting Gram-negative organism in the SENTRY Antimicrobial Surveillance Program between 1997 and 2001 (7). Epidemic clusters of S maltophilia BSIs and pneumonia were reported in participating institutions of the SENTRY Antimicrobial Surveillance Program. Tan et al (8) noted an $85 \%$ increase in nosocomial S maltophilia BSIs over a five-year period
TABLE 3

Minimum inhibitory concentrations of trimethoprim/ sulphamethoxazole (TMPISMX), doxycycline and ticarcillin/ clavulanate for isolates from 2005 to 2009

\begin{tabular}{lccc}
\hline $\begin{array}{l}\text { Year isolate } \\
\text { collected }\end{array}$ & $\begin{array}{c}\text { TMP/SMX, } \\
\mathbf{m g} / \mathbf{L}\end{array}$ & $\begin{array}{c}\text { Doxycycline, } \\
\mathbf{m g} / \mathbf{L}\end{array}$ & $\begin{array}{c}\text { Ticarcillin/clavulanate, } \\
\mathbf{m g} / \mathbf{L}\end{array}$ \\
\hline $\mathbf{2 0 0 5}$ & $>2(\mathrm{R})$ & $>16(\mathrm{R})$ & $>64(\mathrm{R})$ \\
2010 & $16(\mathrm{R})$ & $16(\mathrm{R})$ & $>256(\mathrm{R})$ \\
2005 & $2(\mathrm{~S})$ & - & $16(\mathrm{~S})$ \\
2010 & $1(\mathrm{~S})$ & $4(\mathrm{~S})$ & $64(\mathrm{I})$ \\
2006 & $>2(\mathrm{R})$ & $32(\mathrm{R})$ & $16(\mathrm{~S})$ \\
2010 & $>64(\mathrm{R})$ & $16(\mathrm{R})$ & $32(\mathrm{I})$ \\
2007 & $0.06(\mathrm{~S})$ & $2(\mathrm{~S})$ & $32(\mathrm{I})$ \\
2010 & $2.52(\mathrm{~S})$ & $2(\mathrm{~S})$ & $64(\mathrm{I})$ \\
2007 & $0.12(\mathrm{~S})$ & $2(\mathrm{~S})$ & $16(\mathrm{~S})$ \\
2010 & $2.52(\mathrm{~S})$ & $4(\mathrm{~S})$ & $16(\mathrm{~S})$ \\
2008 & $0.12(\mathrm{~S})$ & $2(\mathrm{~S})$ & $128(\mathrm{R})$ \\
2010 & $2.52(\mathrm{~S})$ & $4(\mathrm{~S})$ & $>256(\mathrm{R})$ \\
2008 & $1.25(\mathrm{~S})$ & $4(\mathrm{~S})$ & $16(\mathrm{~S})$ \\
2010 & $2.52(\mathrm{~S})$ & $4(\mathrm{~S})$ & $4(\mathrm{~S})$ \\
2009 & $1.25(\mathrm{~S})$ & $2(\mathrm{~S})$ & $32(\mathrm{I})$ \\
2010 & $2.52(\mathrm{~S})$ & $2(\mathrm{~S})$ & $32(\mathrm{I})$ \\
2009 & $2.52(\mathrm{~S})$ & $8(\mathrm{I})$ & $32(\mathrm{I})$ \\
2010 & $2.52(\mathrm{~S})$ & $4(\mathrm{~S})$ & $32(\mathrm{I})$ \\
\hline
\end{tabular}

I Intermediate; R Resistant; S Susceptible

at a Taiwanese tertiary care centre, Rolston et al (9) reported a 5\% increase in the proportion of S maltophilia BSIs from 1986 to 2002 at a cancer centre in Texas (USA) and Safdar and Rolston (10) reported a 13\% increase in S maltophilia BSIs from 1998 to 2004 at another institution in Texas. The isolation rate of S maltophilia BSI in Canada in 1999 was reported to be $0.6 \%$ (7). Most studies of S maltophilia as an opportunistic nosocomial pathogen use select groups of patients (eg, hematology, ICU), with many studies combining colonization and infection. The present study encompassed all of the patient populations in the hospital with S maltophilia BSIs and indicates that the isolation rate at this centre has remained lower $(0.05 \%$ to $0.1 \%)$ than the national rate reported in 1999. Contrary to the increasing trends reported in the literature, the trend at our institution has shown a decrease (Figure 1). This was unexpected because our institution is one of the largest transplant centres in the country, which houses the largest cancer institute in the province, as well as four ICUs. There are, as a result, a large number of patients with complex medical problems requiring prolonged hospitalization and broad-spectrum antibiotics.

The wide age range of patients included in the present study indicates that age, per se, is likely not a predisposing factor for development of S maltophilia infection. Garcia Paez and Costa (11) found duration of therapy with broad-spectrum antibiotics, central venous access devices, mechanical ventilation and severe neutropenia to be independent risk factors for Stenotrophomonas infection. In the present study, the majority of the patients were mechanically ventilated (52\%), and the most common comorbidity was neutropenia (25\% [six of 24]).

The majority $(85 \%)$ of the primary BSIs were catheter related, similar to what was found in previous studies $(3,12,13)$. This is not surprising because $S$ maltophilia is known to produce a diffusible signalling factor, which was shown to be responsible for the virulence factors of biofilm formation and resistance to heavy metals in vitro (14) and, as a result, $S$ maltophilia can tolerate silver-lined catheters.

A slightly higher percentage of BSIs in the present study were polymicrobial (44\% [11 of 25]) compared with the $20 \%$ to $40 \%$ quoted in the literature (3). In contrast to other studies $(6,15)$, polymicrobial infections were associated with a higher mortality rate (45.5\% [five of 11]) when compared with monomicrobial infections (15.4\% [two of 13]). This may be indicative of the patients' critical state of illness and/or multiorgan failure. 


\begin{tabular}{|c|c|c|}
\hline Location (range), (reference) & TMPISMX & Ticarcillin/clavulanate \\
\hline Worldwide (1997-2003), (19) & 4.7 & 44.3 \\
\hline UAH, Canada (1999-2009) & 8.3 & 15 \\
\hline United States (1997-1999), (15) & 5 & 10 \\
\hline Latin America (1997-1999), (19) & 2 & 13 \\
\hline Europe (1997-1999), (19) & 10 & 14 \\
\hline Asia-Pacific (1997-1999), (19) & 8 & 29 \\
\hline Taiwan (1999-2003), (20) & 24 & 36 \\
\hline Spain (1995-1998), (21) & 27 & 47 \\
\hline Turkey (1995-2005), (22) & 15 & 30 \\
\hline
\end{tabular}

Data presented as \%. TMP/SMX Trimethoprim/sulphamethoxazole

Garcia Paez and Costa (11) report hematological malignancies and ICU admission as independent risk factors associated with mortality in all S maltophilia infections. Mortality attributable to $S$ maltophilia BSIs could not be established because all four of the patients who died of sepsis had polymicrobial infections. If all polymicrobial infection deaths were attributed to $S$ maltophilia, the rate would be $16.7 \%$ (four of 24 ), which is lower than the reported rates of $20 \%$ to $25 \%$ (11). All of these patients were in the ICU. Fifty per cent of the BSI-attributable deaths (two of four), as well as $50 \%$ (three of six) of all deaths occurred in patients with haematological malignancies.

Susceptibility testing of S maltophilia is difficult to interpret, making treatment decisions based on MICs problematic. The various bodies setting laboratory standards have different susceptibility testing standards, different drugs selected for testing and reporting, and different breakpoint interpretations. CLSI (16) provides testing standards for TMP/SMX, levofloxacin, minocycline, ticarcillin/ clavulanate and ceftazidime, whereas the European Committee on Antimicrobial Susceptibility Testing (17) considers S maltophilia to be intrinsically resistant to cephalosporins and the British Society for Antimicrobial Chemotherapy (18) only provides breakpoints for TMP/SMX. The laboratory at our centre uses CLSI susceptibility testing standards and breakpoints. Although resistance to TMP/SMX in the present study was above the $2 \%$ previously reported among Canadian isolates from 1997 to 1999 and above the average reported worldwide rate of $4.7 \%$ (1997 to 2003) $(5,19)$, it is at the lower end of the reported range of $4 \%$ to $100 \%$ (5) (Table 4). Of note, none of the Canadian TMP/SMX resistant $S$ maltophilia strains from the

\section{REFERENCES}

1. Spencer RC. The emergence of epidemic, multiple-antibioticresistant Stenotrophomonas maltophilia and Burkholderia cepacia. J Hosp Infect 1995;30:453-64.

2. Barchitta M, Cipresso R, Giaquinta L, et al. Acquisition and spread of Acinetobacter baumannii and Stenotrophomonas maltophilia in intensive care patients. Int J Hyg Environ Health 2009;212:330-7.

3. Nyc O, Matejkova J. Stenotrophomonas maltophilia: Significant contemporary hospital pathogen - review. Folia Microbiol 2010;55:286-94.

4. Centers for Disease Prevention and Control. National Hospital Surveillance Network website. <www.cdc.gov/nhsn/> (Accessed November 30, 2010).

5. Looney WJ, Narita M, Muhlemann K. Stenotrophomonas maltophilia: An emerging opportunist human pathogen. Lancet Infect Dis 2009;9:312-23.

6. Micozz1 A, Venditti M, Monaco M, et al. Bacteremia due to Stenotrophomonas maltophilia in patients with haematologic malignancies. Clin Infect Dis 2000;31:705-11.

7. Gales AC, Jones RN, Forward KR, Linares, J, Sader HS, Verhoef J. Emerging importance of multidrug-resistant Acinetobacter species and Stenotrophomonas maltophilia as pathogens in seriously ill patients: Geographic patterns, epidemiological features, and trends in the SENTRY Antimicrobial Surveillance Program (1997-1999). Clin Infect Dis 2001;32(Suppl 2):S104-13.
SENTRY study were isolated from the blood, indicating an increase in invasive infection with resistant strains. Our rate of ticarcillin/ clavulanate resistance is among the lowest reported in the literature and has remained constant since 1997. The MIC trends over the past five years have remained constant (Table 3). The difference in MIC values for TMP/SMX obtained on repeat testing can be attributed to different calculation and reporting methodologies used by the laboratory on initial testing of the isolates and some observer difference owing to the complexity of reading TMP/SMX susceptibility tests.

To further complicate treatment, there is uncertainty of the clinical relevance of in vitro susceptibility tests owing to the lack of controlled trials (5), as shown by one of the study patients whose $S$ maltophilia isolate tested resistant to TMP/SMX, but the bacteremia cleared with TMP/SMX therapy (Table 2).

The present study has several limitations. Due to the small number of cases, the study was not powered to determine risk factors for development of S maltophilia infection. Second, it was a single-centre study at a tertiary care institution, precluding generalization of the data. The retrospective design of the present infection control surveillance and improvement study limited the authors to information legibly written in charts. Daily blood cultures were not drawn from all patients; thus, the duration of bacteremia may have been overestimated in some patients. The cause of mortality was not consistently documented and had to be inferred in some cases. BSI was considered to be the cause of death when the patient died within $24 \mathrm{~h}$ to $48 \mathrm{~h}$ of having a positive blood culture drawn, the vital signs recorded indicated sepsis, and there was no record of a negative blood culture before death.

\section{CONCLUSIONS}

The rate of S maltophilia BSI at our centre remains low and constant. Patients developing S maltophilia BSIs are generally severely ill patients with prolonged hospital stays. The mortality in these patients is high. The MICs for TMP/SMX remain stable with low resistance rates compared with many other countries and it is still considered to be an acceptable first-line antimicrobial at our institution.

ACKNOWLEDGEMENTS: The authors thank the staff of the UAH Infection Control office, and Betty Lui and the staff of the Alberta Provincial Laboratory North.

DISCLOSURES: The authors received no financial assistance for this project and have no conflicts of interest to declare.

8. Tan CK, Liaw SJ, Yu CJ, Teng LJ, Hsueh PR. Extensively drug resistant Stenotrophomonas maltophilia in a tertiary care hospital in Taiwan: Microbiologic characteristics, clinical features, and outcomes. Diag Microbiol Infect Dis 2008;60:205-10.

9. Rolston KVI, Elting L, Waguespack S, Ho DH, LeBlanc B, Bodey GP. Survey of antibiotic susceptibility among gram-negative bacilli at a cancer center. Chemotherapy 1996;42:348-53.

10. Safdar A, Rolston KV. Stenotrophomonas maltophilia: Changing spectrum of a serious bacterial pathogen in patients with cancer. Clin Infect Dis 2007;45:1602-09.

11. Garcia Paez JI, Costa SF. Risk factors associated with mortality of infections caused by Stenotrophomonas maltophilia: A systematic review. J Hosp Infect 2008;70:101-8.

12. Chaplow R, Palmer B, Heyderman R, Moppet J. Stenotrophomonas maltophilia bacteraemia in 40 haematological patients: Risk factors, therapy and outcome. Bone Marrow Transplant 2010;45:1109-10.

13. Lai CH, Wong WW, Chin C, et al. Central venous catheter-related Stenotrophomonas maltophilia bacteremia and associated relapsing bacteremia in haematology and oncology patients. Clin Microbiol Infect 2006;12:986-91.

14. Fouhy Y, Scanlon K, Schouest K, et al. Diffusible signal factor dependent cell-cell signaling and virulence in the nosocomial pathogen Stenotrophomonas maltophilia. J Bacteriol 2007;189:4964-8. 
15. Garcia Paez JI, Tengan FM, Barone AA, Levin AS, Costa SF. Factors associated with mortality in patients with bloodstream infection and pneumonia due to Stenotrophomonas maltophilia. Eur J Clin Microbiol Infect Dis 2008;27:901-6.

16. Clinical and Laboratory Standards Institute. 2010. Performance standards for antimicrobial susceptibility testing; twentieth informational supplement. M100 - S20;v30(1):29.

17. Clinical breakpoints - bacteria (v1.3). European Committee on Antimicrobial Susceptibility Testing (EUCAST). <www.eucast.org/ fileadmin/src/media/PDFs/EUCAST_files/Disk_test_documents/ EUCAST_breakpoints_v1.3_pdf.pdf $>$ Published 2010. (Accessed December 20, 2010).

18. Standardized Disc Susceptibility Testing. British Society for Antimicrobial Chemotherapy (BSAC). <www.bsac.org.uk/ Resources/BSAC/steno.pdf> (Accessed December 20, 2010).
19. Sader HS, Jones RN. Antimicrobial susceptibility of uncommonly isolated non-enteric gram-negative bacilli. Int J Antimicrob Agents 2005;25:95-109.

20. Lai $\mathrm{CH}$, Chi CY, Chen HP, et al. Clinical characteristics and prognostic factors of patients with Stenotrophomonas maltophilia bacteremia. J Microbiol Immunol Infect 2004;37:350-8.

21. Valdezate S, Vindel A, Loza E, Baquero F, Cantón R. Antimicrobial susceptibilities of unique Stenotrophomonas maltophilia clinical strains. Antimicrob Agents Chemoth 2001;45:1581-4.

22. Güriz H, Ciftçi E, Ayberkin E, et al. Stenotrophomonas maltophilia bacteraemia in Turkish children. Ann Trop Paediatr 2008;28:129-36 


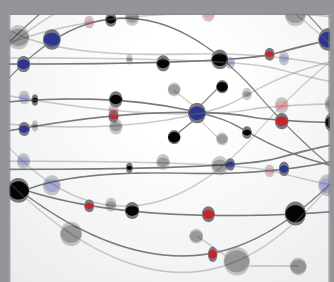

The Scientific World Journal
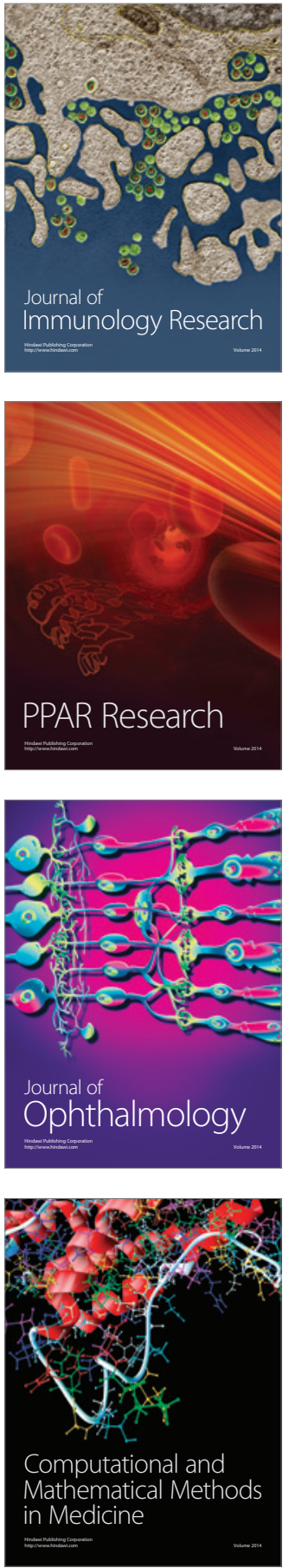

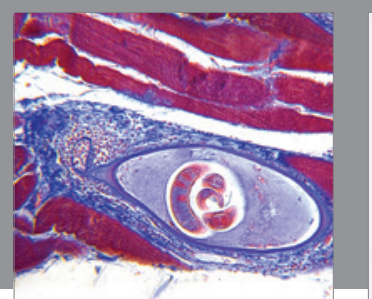

Gastroenterology Research and Practice

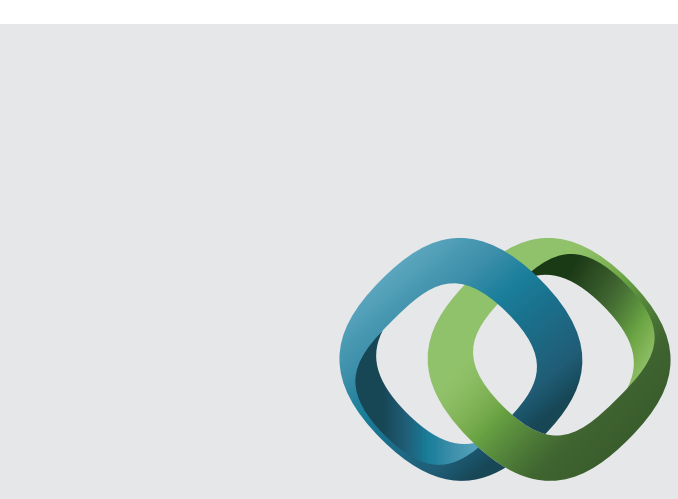

\section{Hindawi}

Submit your manuscripts at

http://www.hindawi.com
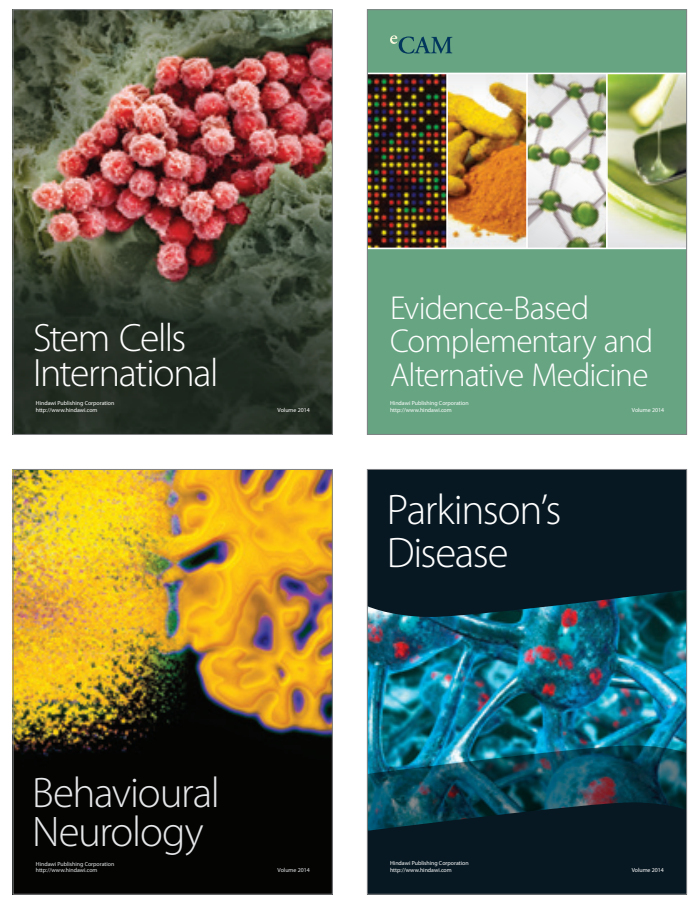
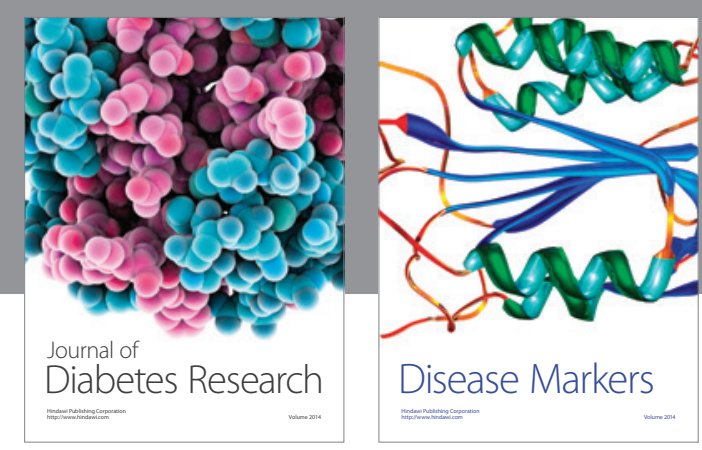

Disease Markers
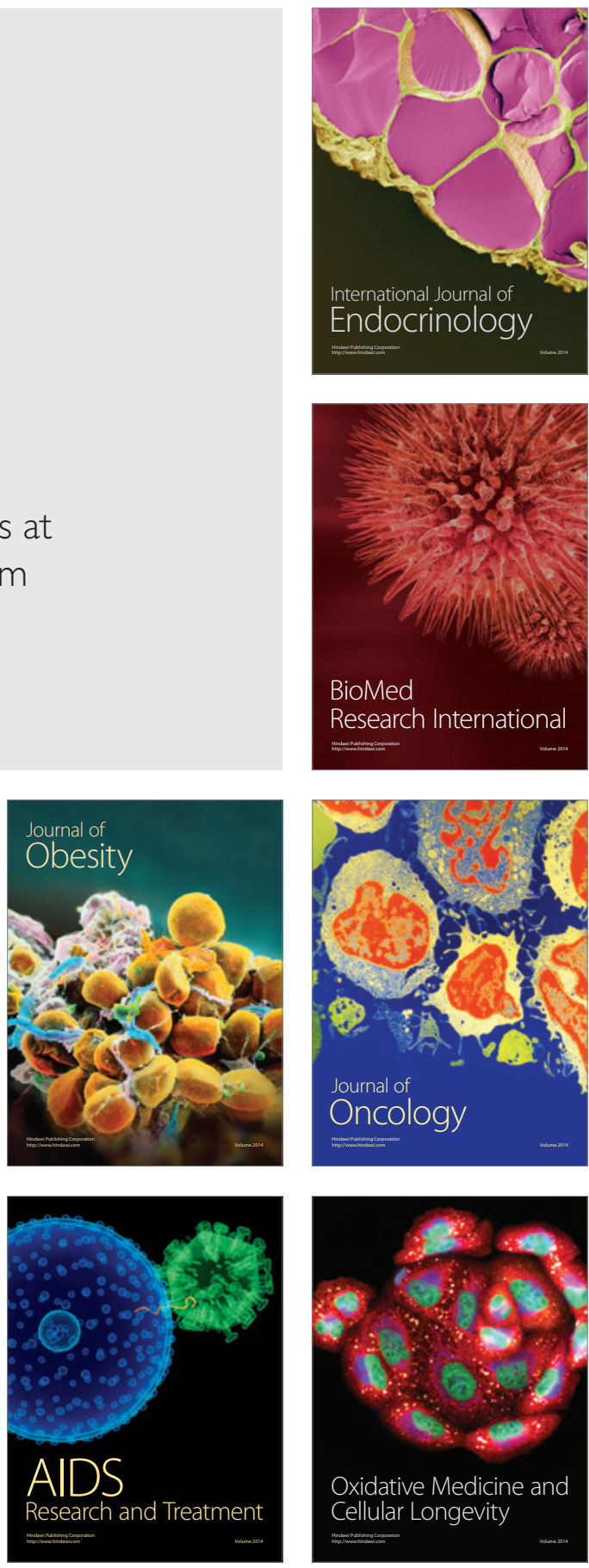